\title{
O Labor Comum em uma situação proposta pela Early Álgebra: mobilização de meios
}

\section{semióticos e colaboração humana}

\author{
Renata Aparecida de Faria1 ${ }^{1}$ \\ UEL, Universidade Estadual de Londrina, Paraná , Brasil
}

\section{Resumo}

O presente artigo apresenta o recorte de uma investigação a respeito do Labor Comum a partir de uma situação proposta no contexto da Early Álgebra denominada "Quantos telefonemas?". A pesquisa está fundamentada nos pressupostos teóricos e metodológicos da Teoria da Objetivação (TO), proposta por Luis Radford. A TO se insere enquanto teoria de ensino e aprendizagem de matemática como uma abordagem semiótica com enfoque sociocultural. Os objetivos da pesquisa são os meios semióticos mobilizados na situação e indícios de características do Pensamento Algébrico. A busca por evidências relacionadas ao Labor Comum é analisada com base nas relações dialéticas entre estudantes e pesquisadora e dos diferentes meios semióticos (gestos, artefatos, representações) produzidos por estudantes de $6^{\circ}$ ano de uma escola da Rede Pública, situada no Norte do estado do Paraná. Considerando os movimentos dialéticos e a mobilização e produção dos meios semióticos, inferimos que existem indicativos dos processos de objetivação e subjetivação de maneira simultânea enquanto constituintes do Labor Comum, além de uma característica do Pensamento Algébrico.

Palavras-chave: Early Álgebra; Labor Comum; Meios Semióticos.

\section{The Common Labor in a situation proposed by Early Algebra: mobilization of semiotic means} \section{and human collaboration}

\begin{abstract}
This article presents an outline of an investigation about the Common Labor based on a situation proposed in the context of Early Algebra called "How many calls?". The research is based on the theoretical and methodological assumptions of the Objectification Theory (TO), proposed by Luis Radford. TO is inserted as a theory of teaching and learning mathematics as a semiotic approach with a socio-cultural focus. The objectives of the research are the semiotic means mobilized in the situation and indications of characteristics of Algebraic Thought. The search for evidence related to the Common Labor is analyzed based on the dialectical relationships between students and researcher and the different semiotic means (gestures, artifacts, representations) produced by 6th grade students from a public school, located in the north of the state of Paraná. Considering the dialectical movements and the mobilization and production of semiotic means, we infer that there are indicative of the processes of objectification and subjectification simultaneously as constituents of the Common Labor, in addition to a characteristic of Algebraic Thought.
\end{abstract}


Keywords: Early Algebra; Common Labor; Semiotic Media.

\section{El trabajo común en una situación propuesta por Álgebra Temprana: movilización de medios semióticos y colaboración humana}

\section{Resumen}

Este artículo presenta un esquema de una investigación sobre el Trabajo Común basado en una situación propuesta en el contexto de Álgebra Temprana llamada "¿Cuántas llamadas?”. La investigación se basa en los supuestos teóricos y metodológicos de la Teoría de la Objetificación (TO), propuesta por Luis Radford. La TO se inserta como una teoría de la enseñanza y el aprendizaje de las matemáticas como un enfoque semiótico con un enfoque sociocultural. Los objetivos de la investigación son los medios semióticos movilizados en la situación y las indicaciones de características del Pensamiento Algebraico. La búsqueda de evidencias relacionadas con el Trabajo Común se analiza a partir de las relaciones dialécticas entre estudiantes e investigador y los diferentes medios semióticos (gestos, artefactos, representaciones) producidos por estudiantes de 6o año de una escuela pública, ubicada en el norte del estado de Paraná. Considerando los movimientos dialécticos y la movilización y producción de medios semióticos, inferimos que son indicativos de los procesos de objetivación y subjetivación simultáneamente como constituyentes del Trabajo Común, además de una característica del Pensamiento Algebraico.

Palabras clave: Álgebra temprana; labor común; medios semióticos.

\section{Introdução}

No cenário contemporâneo, diversas pesquisas no âmbito da Educação Matemática estão fundamentadas sob perspectivas semióticas, dentre elas: as investigações em Didática da Matemática de Bruno D’Amore, a respeito dos elementos semióticos presentes nas aulas de Matemática; a Teoria dos Registros de Representação Semiótica de Raymond Duval, cujo foco são os diferentes registros de representação e as atividades cognitivas de tratamento e conversão; os Enfoques Ontosemióticos de Juan D. Godino, que abordam os significados dos objetos matemáticos no contexto escolar e institucional; o Semiotics Bundle de Ferdinando Arzarello, quanto a multimodalidade, e a Teoria da Objetivação, de Luís Radford, com enfoque social e cultural.

Conforme D’Amore (2015, p.20), “[...] toda investigação em Didática da Matemática tem que ser cognitiva e social, individual e coletiva, antropológica e cultural; mas, de agora em diante, terá que ser também semiótica”. Segundo Radford (2015), a semiótica permite compreender que tais processos não são realizados simplesmente por meio do simbolismo matemático. Nesses processos intervém outros tipos de signos, como os gestos, as palavras, a entonação, o ritmo e outros signos corporais.

Para Santaella (2005) a semiótica é a ciência que tem por objeto de investigação todas as linguagens possíveis, ou seja, que tem por objetivo o exame dos modos de constituição de todo e qualquer fenômeno - enquanto produção de significação e de sentido. 
Dentre as teorias citadas, neste trabalho, assume-se a Teoria da Objetivação (TO) enquanto fundamentação teórica-metodológica na condução de uma pesquisa de doutorado em andamento, cuja investigação é o Labor Comum - unidade fundamental da TO - a partir de uma situação proposta no contexto da Early Álgebra, que se constitui como um movimento do ensino da Álgebra para crianças, desde o Ensino Fundamental I, todavia, não se trata de ensinar Álgebra para crianças pequenas, tampouco priorizar a Álgebra em detrimento da aritmética, mas promover situações que possibilitem a construção do Pensamento Algébrico.

A TO é considerada uma abordagem semiótica que entende os objetos do conhecimento frente ao estudante enquanto potencialidade de aprendizagem, tal como a regularidade de uma expressão algébrica em uma sequência numérica. Ao lançar mão da abordagem semiótica da TO, os processos de significação que constituem a Álgebra, por exemplo, nos quais se lançam os estudantes quando procuram compreender as formas de raciocínio matemático, podem ser abrangidos na sua construção histórica e cultural.

A semiótica não se constituiu direcionada às questões educacionais. Por ser uma teoria de significação - o modo como os signos significam - pode fornecer insights sobre a maneira pela qual as práticas educacionais funcionam. Na TO, a ideia de signo é a proposta por Vygotsky (1984) que enfatiza nos signos seu papel funcional (não meros auxiliares para executar uma tarefa ou resolver um problema), mas sim como ferramenta psicológica e mediadora cultural.

Nesse tipo de abordagem, a aula de Matemática é considerada como produtora de conhecimentos e de subjetividades, demarcando a dimensão do saber (conhecimento) e do ser (sujeitos). Pesquisas recentes indicam uma amplitude de temas e disciplinas cujos pressupostos teóricos, epistemológicos, ontológicos e metodológicos presentes nessas investigações não se restringem à Matemática, como por exemplo o enfoque no Pensamento Algébrico (VERGEL, 2014) e orientação espacial (PAIVA, 2020) no Ensino de Matemática. Em Física, tem-se o uso do GeoGebra por Noroño (2020). No Ensino de Ciências, Nogueira (2019) investiga a relação de um episódio da ficção científica na formação de professores sob a luz da TO. Camilotti e Gobara (2020) investigam o processo de subjetivação na Formação de Professores de Ciências e Matemática e no Ensino de Geografia, Castilho (2020) analisa o mapa cartográfico enquanto um sistema semiótico sob o viés da TO,

Diante da representatividade de pesquisas recentes sob o referencial da TO, apresenta-se um recorte de uma pesquisa de doutorado cuja questão investigativa são os elementos que emergem de uma situação do contexto da Early Álgebra denominada “Quantos telefonemas?”, com estudantes do $6^{\circ}$ ano, sob o viés da Teoria da Objetivação. 
Os objetivos da pesquisa consistem na identificação dos processos de objetivação e subjetivação decorrentes do Labor Comum, os meios semióticos mobilizados e indícios de características do Pensamento Algébrico.

O desenvolvimento do Pensamento Algébrico é processual e a relevância de desenvolver o mesmo desde o Ensino Fundamental II, Anos Iniciais, é no sentido de considerar que iniciar a Álgebra simbólica no $8^{0} / 9^{0}$ ano do Ensino Fundamental (13/14 anos) pode vir a inibir a produção de significados pelos estudantes.

A busca por evidências relacionadas ao Labor Comum é analisada com base nas relações dialéticas entre os estudantes e a pesquisadora e dos diferentes meios semióticos (gestos, artefatos, representações) produzidos por estudantes do $6^{\circ}$ ano de uma escola da Rede Pública, situada no Norte do Paraná.

A estrutura do artigo é composta pela revisão de literatura, constituída por dois temas: o Pensamento Algébrico e a TO. No primeiro tema, tem-se uma descrição de discussões a respeito de características do Pensamento Algébrico, o contexto da Early Álgebra e indicações sobre o Pensamento Algébrico presentes nos Documentos Oficiais. O segundo concentra-se nos princípios ontológicos, epistemológicos e metodológicos que orientam a TO. Em seguida, apresentam-se os procedimentos metodológicos da pesquisa, os resultados e análise das produções dos estudantes, que são expostos no penúltimo item, seguido das considerações finais e referências bibliográficas.

\section{Revisão da Literatura}

\section{O Pensamento Algébrico e a Early Álgebra}

No início dos anos 1990, pesquisadores nacionais e internacionais, como Kaput e Carraher (2008), Kieran (1992), Lins (1997) e Radford (2015), propõem-se a investigar o Pensamento Algébrico quanto à sua constituição, metodologias apropriadas e em que sentido mudanças e/ou adaptações curriculares nos diferentes níveis de ensino são necessárias.

A definição do que é o Pensamento Algébrico e suas possíveis caracterizações não encontra respostas similares dentre os investigadores do tema, pois depende do que o pesquisador considera relevante para o ensino e aprendizagem da Álgebra Escolar.

Tais pesquisas indicam que uma definição seria limitante, pois a amplitude desse conceito envolve ideias de padrões, regularidades, sequências, raciocínio, equações, cálculos aritméticos, expressões, fórmulas, relação entre termos, valor desconhecido, modelos matemáticos, variação e covariação. Lins e Gimenez (1997,p.169), por exemplo, salientam que na escrita algébrica “[...] uma notação deve, então, ser legítima e adequada, e nesse processo é que ela vai se “carregando' de 
significados, o que quer dizer que se transforma em objeto para a pessoa, um objeto que se conhece cada vez melhor".

Porém, um aspecto que a maioria das pesquisas convergem, é quanto a generalização ser a “mola-mestra' do Pensamento Algébrico, ou o coração da Matemática, conforme reforça metaforicamente (MESTRE, 2014). Inúmeros autores, dentre eles VERGEL (2014) e RADFORD (2006), investigam a generalização em situações de comunalidade entre padrões, sequencias recursivas e sequencias não recursivas; em que destacam as situações propostas para a promoção da capacidade de abstração, comunicação, raciocínio matemático, mobilização e produção de representações.

A generalização, enquanto característica principal do pensamento algébrico, e os meios semióticos aos quais recorremos, segundo Radford (2006), são consubstanciais com o nível de generalidade envolvida. Na evolução da matemática diferentes meios semióticos de pedras, riscos, axiomas, escrita alfanumérica e algébrica corroboram essa ideia.

[...] O conhecimento algébrico abrange possibilidades, de se pensar em coisas indeterminadas e que só pode se tornar objeto de pensamento e interpretação apenas se colocado em movimento e ser transformado em um objeto de sentidos e consciência através de atividades específicas de solução de problemas e mediadas por diferentes meios semioticos (RADFORD,2015.p.130).

Nesse sentido, a Early Álgebra apresenta uma proposta de ensino decorrente dos apontamentos de pesquisadores com foco no que possa ser referido como Pensamento Algébrico, sendo acessível a estudantes mais jovens e, consequentemente, auxiliar na eventual transição para o estudo mais formal de Álgebra. Outra consideração é quanto ao ensino de aritmética ser anterior ao da Álgebra, ressaltando que o objetivo não é ensinar a Álgebra primeiro, mas sim reconhecer o caráter algébrico da aritmética.

Além da faixa etária mais jovem, nesse corpo de trabalho há uma mudança sutil na ênfase da caracterização tradicional da Álgebra (centrada no conteúdo) para a promoção dos processos e representações do raciocínio matemático, que pareceriam apropriados para crianças pequenas, bem como para a natureza das primeiras atividades de Álgebra.

Em particular, os principais temas ao longo dos anos, desde o início dos anos 2000, incluem, de acordo com Kaput; Carraher; Blanton (2008): (i) generalização relacionada à atividade de padronização na descrição de relações funcionais envolvendo a percepção de variações e covariações em que a generalização surge pela ideia de função, (ii) generalização relacionada a propriedades de operações e estrutura numérica ,como a comutatividade da adição e multiplicação ; a relação de identidade; e a relação entre quantidades, (iii) representação de relações entre quantidades, relações de igualdade; resolução de expressões numéricas com números desconhecidos; com a ênfase no 
número generalizado considerando sua estrutura e não seu valor, ou seja, tratar o número algebricamente e (iv) introdução de notações alfanuméricas gradualmente.

Carraher et al. (2007) ressaltam que a Early Álgebra não significa simplesmente o ensino da Álgebra mais cedo, e sim uma nova abordagem que envolve uma mudança conceitual. Isso não significa que todas as ideias, conceitos e técnicas aritméticas sejam manifestamente algébricas, mas podem ser potencialmente algébricas. A aritmética não deve ser a única preterida, ou que sejam ensinados apenas os conteúdos de séries subsequentes, mas a partir dos conteúdos dos anos iniciais e que possa ocorrer a integração dos aspectos algébricos, visto que "esta perspectiva nos impele a considerar que os tópicos ou conceitos isolados da aritmética podem fazer parte de ideias e conceitos mais gerais e abstratos" (MESTRE, 2014, p. 11).

Conforme a descrição das característica do Pensamento Algébrico, no Quadro 1, apresentamos indícios quanto as características e ressaltamos que as mesmas não são limitantes, podendo ocorrer outros indícios no desenvolvimento de investigações sobre o tema.

Quadro 1 - Síntese das Características do Pensamento Algébrico de acordo com Kaput; Carraher; Blanton (2008)

\begin{tabular}{c|l}
\hline Características & \multicolumn{1}{c}{ Indícios } \\
\hline Padrões/Regularidades & Identificação e descrição de um padrão numérico. \\
\hline \multirow{2}{*}{ Generalização } & Apresentação da aspectos da generalização. \\
\cline { 2 - 2 } & Utilização linguagem sincopada (utilização de símbolos) \\
\hline \multirow{2}{*}{ Cálculos aritméticos } & Exploração de propriedades das operações com números. \\
\cline { 2 - 2 } & Demonstra raciocínio multiplicativo. \\
\cline { 2 - 2 } & Expressão de raciocínio aditivo. \\
\hline \multirow{2}{*}{ Variação/Covariação } & Determinação de uma relação funcional. \\
\cline { 2 - 2 } & Estabelecimento de correspondência entre quantidades. \\
\hline Relações entre termos & Exploração da igualdade como uma relação entre termos. \\
\hline Valor desconhecido & Resolução de sentenças com números desconhecidos. \\
\hline Modelos matemáticos & Justificação, representação e demonstração de ideias. \\
\hline
\end{tabular}

Fonte: Adaptado Kaput; Carraher; Blanton (2008)

\section{O Pensamento Algébrico e os Documentos Oficiais}

Considerando a necessidade de repensar o ensino da Álgebra Escolar e o desenvolvimento do Pensamento Algébrico, os documentos oficiais sugerem, no âmbito educacional, para os profissionais envolvidos com a Educação, entre eles pedagogos, gestores e professores de Matemática, em diferentes níveis do ensino básico. O trabalho com a Álgebra, desde os Anos Iniciais do Ensino 
Fundamental, evidencia a contribuição para o desenvolvimento de um raciocínio específico, denominado Pensamento Algébrico. Essa ideia atual se diferencia de uma ideia de Álgebra escolar como um processo de manipulação de símbolos, segundo a Base Nacional Curricular Comum (BNCC).

Nessa perspectiva, algumas dimensões do trabalho com a Álgebra estão presentes nos processos de ensino e de aprendizagem, desde os anos iniciais, como as ideias de: regularidade, generalização, equivalência, capacidade de identificar atributos e regras de formação de sequências reconhecimento de mudanças e relações, primeiros indícios da ideia de função (BRASIL, 2018).

O National Council of Teachers Mathematics (NCTM) (USA, 2008) sugere a proposta de situações em que os estudantes possam: a) identificar e descrever padrões verbalmente e representálos com tabelas ou símbolos; (b) procurar e aplicar relações entre quantidades variáveis para fazer previsões; (c) fazer e explicar generalizações (d) usar gráficos para descrever padrões e fazer previsões; (e) utilizar notação inventada, símbolos padrão e variáveis para expressar um padrão, generalização ou situação, indo ao encontro das características e indícios do Pensamento Algébrico presentes no Quadro 1.

No próximo item apresentamos conceitos da Teoria da Objetivação, em que o pensamento é uma prática social e cultural. Para Radford (2018) a concepção de Álgebra e Pensamento Algébrico não se detém a uma manifestação simbólica, abstrata e puramente mental.

\section{A Teoria da Objetivação (TO)}

A TO proposta por Luis Radford (2006, 2017, 2020) é voltada para o ensino e aprendizagem de matemática, e fundamentada em reflexões a respeito de conceitos chaves, como: saber, conhecimento, aprendizagem e o papel dos professores e estudantes no processo educativo. Apresenta uma dimensão sócio/cultural com influência de intelectuais russos, dentre eles Lev Vygotsky (abordagem histórico-cultural) e Evald Ilyenkov (epistemologia cultural), procurando destacar o conceito de alteridade proposto por Emmanuel Levinas.

Segundo Radford (2015, p.132), a concepção de Educação Matemática para a TO é mediada por um esforço político, social, histórico e cultural, de modo processual e dinâmico, na qual a construção de conhecimentos, a partir da concepção do materialismo dialético, que "é uma síntese cultural, dialética e sensorial das pessoas", ou seja, na TO o foco muda conforme estudantes recebem o saber (ensino tradicional) e constroem seu próprio saber (construtivismo), para como professores e estudantes produzem o saber em sala de aula, tendo como pano de fundo, a cultura e a história. Contudo, "o foco também se desloca para a forma como os professores e estudantes coproduzem a si 
mesmos como sujeitos, em geral, e como sujeitos da educação, em particular” (RADFORD, 2017, p. 243).

Entre os princípios teóricos do pensamento que norteiam a TO, que são mencionados por Radford; Schubring; Seeger (2008), destacam-se cinco conceitos, que são explicitados no Quadro 2.

Quadro 2- Princípios do pensamento da TO segundo Radford, Schubring, Seeger (2008)

\begin{tabular}{c|l}
\hline Conceitos & \multicolumn{1}{c}{ Princípios } \\
\hline Filosófico & $\begin{array}{l}\text { A elaboração ocorre de maneira não-mentalista, com base no materialismo } \\
\text { dialético. }\end{array}$ \\
\hline Psicológico & A elaboração se dá enquanto práxis sociais. \\
\hline Ontológico & $\begin{array}{l}\text { Os objetos matemáticos são resultantes das atividades reflexivas de uma prática } \\
\text { sociológica mediada por artefatos. }\end{array}$ \\
\hline Ontogenético & $\begin{array}{l}\text { A objetivação e seu par, a subjetivação de natureza semiótica e cognitiva } \\
\text { ocorrem como uma forma de operacionalizar a teoria. }\end{array}$ \\
\hline Epistemológico & $\begin{array}{l}\text { O processo de ensino e aprendizagem ocorre como um produto cultural, pois a } \\
\text { atividade humana é proveniente dos sistemas semióticos de significação } \\
\text { cultural. }\end{array}$ \\
\hline
\end{tabular}

Fonte: Adaptado de Radford, Schubring, Seeger (2008).

\section{Os processos de Objetivação e Subjetivação}

A objetivação, conforme apontamentos de Radford (2017), é um processo inacabado, em constante construção, que simultaneamente produz subjetividades frente ao objeto de conhecimento. “[...] é precisamente o processo de reconhecimento do que nos objeta (enquanto potencialidade no sentido aristotélico) - sistemas de ideias, significados culturais, formas de pensamento" (RADFORD, 2017, p. 118).

O aspecto semiótico relaciona a objetivação por meio do processo social de tomada de consciência, de algo que não era "notado", e a subjetivação como indissociável da objetivação durante a ação contínua e histórica de criação do eu, do ser social. A subjetivação, assim, seria o devir do eu.

A justaposição de ambos (objetivação e subjetivação) contempla a tríade entre os Sistemas Semióticos Culturais, as Atividades e o Território do Pensamento a partir dos Artefatos.

Um Sistema Semiótico Cultural, ao produzir significações, propicia reflexões a respeito de crenças e concepções sobre os objetos conceituais, métodos de indagações e formas legítimas de representação do conhecimento, dentre outros. As atividades são concebidas de uma maneira particular, singular de cada momento histórico com seus objetivos, ações e divisões de tarefas. Quanto ao pensamento, esse é mediado por artefatos, ou seja, pelos Meios Semióticos de Objetivação: objetos, gestos, atividade perceptiva, linguagem escrita, fala, a posição corpórea dos estudantes e do professor, ritmo e assim por diante. 


\section{A sala de aula na perspectiva da TO}

Segundo Radford (2018), a atividade é um dos alicerces que constitui a TO, ao ser concebida de uma maneira particular. O destaque aqui não é apenas fazer algo, mas o tipo de atividade que coloca em movimento e transforma a potencialidade (o saber) de cada objeto do conhecimento, em objeto de consciência e concretiza a singularidade (subjetivação).

Esse movimento dialético ocorre entre as dimensões do saber (e conhecimento) e a dimensão do ser (e subjetividade), como observa-se na Figura 1.

Figura 1: Relação Dialética de acordo com Radford (2018)
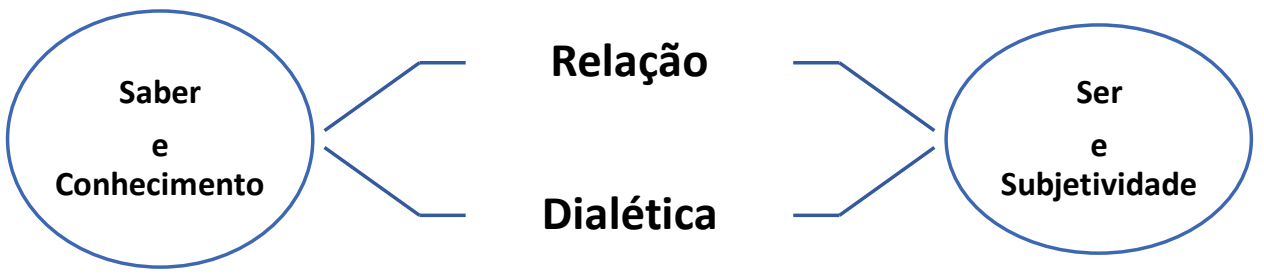

Fonte: adaptado de Radford (2018)

O pensar não ocorre somente de maneira mental, mas, também, de forma social, sublinhando que a subjetivação e objetivação se sobrepõem, em um processo mútuo. A implementação da atividade é precedida pela tríade objeto do conhecimento, objetivo da atividade e tarefas da atividade, em que o design das situações propostas (sua estrutura) direciona ao objeto por meio dos objetivos.

\section{O Labor Comum}

A categoria ontológica principal da TO é a Atividade, denominada Labor Comum, que seria um processo de inscrição dos indivíduos no mundo social e a produção de sua própria existência. Radford (2018, p. 13) afirma que "o individuo não pode ser concebido como uma entidade substancial produzida no interior, tal como se articulam tanto as tendências racionalistas quanto às tendências empiristas humanistas, que constituem a maioria das teorias educativas contemporâneas".

O conceito de Labor Comum permite conceber o ensino e a aprendizagem em sala de aula não como duas ações separadas, uma realizada pelo professor (ação do professor) e outra pelo estudante (ação do estudante), mas como um movimento único: o labor comum entre professorestudante(s) (RADFORD, 2020).

No processo dialético, que envolve professor e estudante(s) há uma interação dinâmica, em que o professor aponta estratégias, ouve com atenção e sensibilidade as sugestões do(s) estudante(s), amplia as discussões para o coletivo da sala de aula, em uma descoberta constante que culmina na 
produção do saber matemático constituído coletivamente, ressignificando-o. Ao respeitar as subjetividades dos estudantes, o professor produz as suas, ancorados nos meios semióticos mobilizados durante o labor comum.

Consequentemente, por meio de processos prolongados de objetivação e subjetivação, os estudantes se envolvem em formas cada vez mais elaboradas de trabalho conjunto e estruturas mais complexas de intersubjetividade (eu, você, você e nós).

Sua atividade semiótica multimodal é organizada e refinada, dando origem a elaboradas formas culturais de percepção, imaginação, discursividade, simbolização e pensamento. Radford (2018) aponta a ética comunitária como indispensável para percepção e participação de um coletivo, com responsabilidade, compromisso e cuidado, assegurando formas de agir /pensar de modo crítico e colaborativo.

Na Teoria da Objetivação o indivíduo é uma entidade histórico-cultural que vai além da pele, é relacional do princípio ao fim. Nesse processo, a atividade da sala de aula é a unidade de análise, em que o papel da linguagem, dos signos, dos artefatos e do corpo não é descartado nos processos de conhecimento e evolução, e sim entendidos não como mediadores, mas como parte da atividade dos indivíduos.

Em um nível prático, o conceito de Labor Comum permite conceber o processo de ensino e a aprendizagem em sala de aula não como duas atividades separadas (uma realizada pelo professor e outra pelo estudante, mas como única: o Labor Comum entre professor-estudante(s).

Mais precisamente, pelo Labor Comum, entendemos não um mero conjunto de ações coordenadas, mas a atividade realizada ombro a ombro pelo professor e pelos estudantes. É uma forma de energia que incorpora o fluxo de componentes emocionais, afetivos, éticos, intelectuais e materiais e dos quais a Matemática aparece sensivelmente na sala de aula (RADFORD, 2018, p. 72).

A noção de Labor Comum exige uma reformulação de atitudes por parte do professor e da Educação Matemática, de maneira geral. O autor sublinha que, nessa perspectiva, o professor não apresenta resposta ao estudante, nem espera a "construção" do entendimento do objeto matemático sozinho. Esses elementos da ética comunitária, segundo Radford (2017, p.157) “ não ocorrem a partir de uma evolução natural, que não é cognitivo ou racional, sendo construtos a partir da forma de alteridade de indivíduos inscritos em certo contexto histórico e cultural".

A concepção sistêmica do Labor Comum consiste na produção de saberes e nas formas de colaboração humana. Os saberes materializados com a mobilização de diferentes meios semióticos pelos envolvido na dinâmica da aula, estão ancorados nas formas de colaboração humana respeitando as subjetividades ocorridas durante o desenrolar da aula (RADFORD, 2020). 
No item a seguir, discorremos a respeito da Ética Comunitária que fundamenta a noção de colaboração humana proposta pela TO.

\section{A Ética comunitária}

Radford (2020) concebe a ética não somente como uma questão pedagógica, mas também da Didática da Matemática. "A ética é concebida como um relacionamento fluído, pessoal e cultural de responsabilidade entre um e outro: ou, de maneira mais geral, como forma de alteridade" (RADFORD, 2020, p.33 grifo do autor).

Nogueira (2019) assinala que as atitudes de natureza ética, que são propostas por Radford (2015, 2017, 2020), potencializam a gestão de maneiras críticas de pensar, agir e se posicionar diante do outro "[...] fundadas em propostas de colaboração humana não egoístas e utilitárias porque pautadas no interesse de exercitar o bem comum, a justeza de ações e o diálogo" (NOGUEIRA, 2019, p.53).

A ética comunitária está estruturada, segundo Radford (2017, 2020), construída por meio da forma de alteridade dos indivíduos inscritos em certo contexto histórico e cultural em três vetores: a responsabilidade, o compromisso e o cuidado com o outro. Esses elementos da ética comunitária não evoluem de forma racional, natural ou individual. A responsabilidade aparece como vinculação, conexão e solicitude ao outro. No compromisso há o empenho na realização do labor comum, o "ombro a ombro" entre professores e estudantes. O cuidado não é um ato de condescendência, e sim o reconhecimento do outro e de suas necessidades.

Radford (2020) assinala que esses elementos da ética comunitária se combinam na criação de um espaço ético, promovendo o labor comum e onde possam emergir novas formas de subjetivação e objetivação.

\section{Metodologia}

A pesquisa apresentada é considerada qualitativa-descritiva, cujas características, segundo Ludke e André (2013), consistem na utilização do ambiente natural como fonte direta de coleta de informações, na predominância descritiva das informações, no destaque maior ao processo do que ao produto e tem o pesquisador como instrumento fundamental para esta coleta.

A metodologia escolhida veio ao encontro do referencial teórico e dos objetivos da pesquisa, na investigação de indícios dos processos de objetivação e subjetivação e de características do Pensamento Algébrico, a partir da mobilização dos meios semióticos. 
Adotamos a TO para a análise das informações, sendo que para essa teoria a unidade metodológica é o Labor Comum, implicando na análise dos meios semióticos como os gestos, signos (desenhos, fórmulas, gráficos), artefatos, ritmos e vozes.

Em consonância à tríade presente na dimensão pedagógica da atividade - objeto, objetivo e tarefas - a escolha da proposta justifica-se por propiciar tarefas de elaboração de representações, objetivando, a partir do Labor Comum, a investigação dos processos de objetivação e subjetivação, além de potencializar as discussões a respeito das características do pensamento algébrico (objeto).

A situação proposta, intitulada "Quantos telefonemas?", foi apresentada aos estudantes na última quinzena de novembro de 2019, em uma escola da Rede Pública de Ensino, de uma cidade do Norte do Paraná-Brasil. Ressaltamos que a pesquisadora também era professora de Matemática das turmas, e a investigação foi conduzida com estudantes do $6^{\mathrm{a}}$ ano do Ensino Fundamental.

O desenvolvimento da proposta ocorreu durante duas aulas de 50 minutos cada, em três turmas de $6^{0}$ ano (denominadas 6TA, 6TB e 6TC), compostas respectivamente por 29, 30 e 31 estudantes. Os estudantes tinham idades entre 10 e 11 anos e trabalharam em grupos, compostos por dois a quatro integrantes.

A escolha dos grupos ficou por conta dos estudantes, cujo critério estabelecido pela pesquisadora foi de ter no máximo quatro pessoas por grupo. A pesquisadora sugeriu que os estudantes poderiam se reunir nas mesas do pátio da escola, devido ser um local maior e arejado, com boa iluminação e quadro de giz, o que foi aceito por todas as turmas.

A recolha das informações ocorreu por meio de gravações em áudio, e cada grupo utilizou aparelhos smartphones para fazê-las, além de anotações em diários da pesquisadora e protocolos dos grupos.

Em “Quantos telefonemas?” foi proposta a seguinte atividade, adaptada de Canavarro (2007, p. 82), em uma folha de sulfite:

Considere que 5 amigos desejam ligar uns para os outros para desejar Feliz Ano Novo. Quantas ligações podem ser feitas?

A pesquisadora indicou que os grupos poderiam escolher por desenvolver a proposta na mesma folha. Inicialmente, a resolução de muitos grupos foi de 5 telefonemas como resolução da situação. Fizemos a proposta de resolução no quadro de giz, o que foi prontamente aceito.

Alguns grupos das turmas 6TA e 6TB refizeram a proposta com a utilização de diferentes artefatos: papéis coloridos, cola, tesouras, copos de plástico, pedaços de papelão, lápis de cor, canetas diversas e tintas.

Considerando as três turmas tivemos um total de 17 resoluções (5 resoluções do 6TA, 6 do 6TB e 6TC). No presente artigo optamos por indicar a resolução de um grupo de cada turma, ou seja, 
três resoluções distintas da situação proposta, analisando diversos meios semióticos, construção de modelos e interações dialógicas entre os envolvidos: pesquisadora $(\mathrm{P})$ e estudantes (nomeados como $\mathrm{E} 1, \mathrm{E} 2, \ldots)$.

As resoluções serão apresentadas na ordem alfabética das turmas 6TA, 6TB e 6TC e respectivos grupos - indicados por G1, G2, G3,.., seguidas de inferências quanto aos meios semióticos e indícios dos processos de objetivação e subjetivação e das características do Pensamento Algébrico.

\section{Resultados e análises}

Dentre os meios semióticos mobilizados no desenvolvimento da situação "Quantos telefonemas?", destacaram-se os gestos, modelos em 3D e as representações indicadas enquanto Representações Regulares e Representações Idiossincráticas.

Consideramos que as Representações Regulares são aquelas de utilização recorrentes em outras situações matemáticas, ou seja, representações descritivas escrita, tabular, gráfica, aritmética, algébricas , enquanto as Representações Idiossincráticas são produzidas pelos estudantes de maneira singular como: desenhos, diagramas, esquemas.

As representações idiossincráticas são construídas pelos estudantes, à medida que resolvem problemas e investigam ideias matemáticas, e, segundo Mestre (2014, p.44), “[...]podem desempenhar um papel bastante importante ajudando os estudantes na compreensão e na resolução de problemas, e proporcionando formas significativas para registrar um método de resolução e para o descrever a outros".

Iniciamos a interpretação dos resultados e análises com o Grupo 1 (6TA), que produziu uma representação idiossincrática, ou seja, uma representação única, conforme protocolo da Figura 2, ao mesclar desenhos simbolizando as pessoas da situação "Quantos telefonemas?", uma legenda colorida indicando a quantidade de ligações de cada pessoa e um algoritmo de adição como resultado do total de ligações.

Antes dessa produção o grupo resolveu utilizar papéis coloridos e copos para indicação do total de telefonemas, em que cada copo seria uma pessoa,e, assim, no primeiro copo teriam quatro pedaços de papéis, no segundo copo dois papéis, e assim sucessivamente.

Na Figura 2, observa-se que o Grupo 1 indica o total de ligações a partir das cinco pessoas utilizando desenhos, nomes, legendas, traços coloridos e o algoritmo de adição. 
Figura 2 - Representação Idiossincrática do Grupo 1

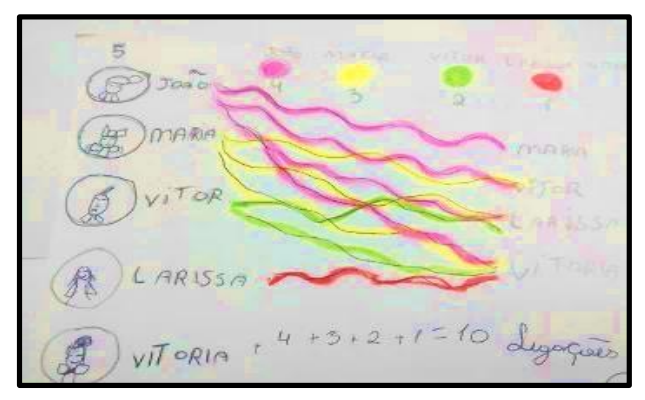

Fonte: protocolo do Grupo1.

A seguir, no excerto, constam as interações dialógicas entre os estudantes e a pesquisadora.

$P:$ Vocês representaram de várias maneiras!

E4: Ahhh... A gente pensou nos nomes dos amigos e fez as cores e os copinhos (mostra o modelo $3 D$ colorido e os copos).

E1: Dai foi "ligando" cada pessoa e a cor com quem ia falar, tipo (mostra para a pesquisadora com o lápis os traços) o João com o rosa ligou 4 vezes , então 4 "linhas”!

E3: Foi só contar quantas ligações ( indica com o dedo a quantidade de papéis em cada copo e as "linhas' coloridas) [...].

P: E se fossem mais pessoas?

E2: Só desenhar mais alguém e contar [...].

E2: Olha é assim: 4 pessoas ( faz o algoritmo $3+2+1$ em um rascunho), 5 pessoas tem aqui (indica na folha), então 6 junta $5+4+3+2+1$, né?( Olhando para os outros integrantes).

E3:Sim [...], sempre o depois soma!

E1: Que "depois"?

E3: Assim (indicando com o lápis) [...] 5 pessoas dá 10, soma o de antes 4 pessoas (mostra o exemplo do rascunho que totalizou 6 telefonemas), e pra saber 6 pessoas soma 5 (pessoas de antes ) com os 10 telefonemas [...].

\section{E4: Nossa! Dá certo para outras pessoas [...].}

Destaca-se que a indicação com o lápis do estudante E1, vem ao encontro do que Goldin (2002) sinaliza que uma representação pode servir como metáfora denotando uma situação e / ou simbolizando- a, relacionando as mesmas com representações próprias da matemática - como o algoritmo da adição presente no protocolo.

De acordo com as considerações do Grupo 1 quanto a soma da linha anterior, em que quatro pessoas totalizam seis telefonemas, e para cinco pessoas adiciona-se quatro - quantidade de pessoas menos um - ao valor anterior, indica-se indícios do Pensamento Álgebrico quanto a co-variação, ou Revista de Educação Matemática, São Paulo, SP, v. 18, 2021, p.1-23 - e021007 
seja, a relação entre as variáveis - telefonemas e pessoas presentes nos desenhos, linhas coloridas, e algoritmos.

Recordamos que para a TO os objetos matemáticos são historicamente gerados durante a atividade matemática dos individuos. Radford (2006) sublinha que a fórmula é a cristalização de um processo semiótico dotado de uma história, em que a expressão algébrica ainda não foi simplificada pelos estudantes. Nesse sentido, a co-variação na situação “Quantos telefonemas?” poderia também ser escrita na forma algébrica $\boldsymbol{f}(\boldsymbol{n})=\frac{n^{2}-\boldsymbol{n}}{2}$, em que (n) indica o número de pessoas e $\mathrm{f}(\mathrm{n})$ a quantidade de telefonemas.

O foco de investigação não é a escrita algébrica simbólica, e sim significar a proposta de modo que haja objetivação, enquanto processo de estar frente ao que saber enquanto potencialidade, nesse caso, a relação entre as variáveis pessoas e telefonemas. A distinção entre os conceitos chaves de saber e conhecimento, segundo o autor, é que “o saber é potencialidade cultural, potencialidades (de algo que pode acontecer), de pensar o mundo e que serão atualizadas pelo conhecimento através da prática social (ato)”. (RADFORD, 2015, p.252)

Para a TO o saber é materializado em conhecimento com a mobilização e /ou produção de meios semióticos, que no Grupo 1 foram: as representações, o modelo com copos, os gestos indicativos com o lápís, a expressão facial interrogativa de E2 ao explicar a soma para os colegas, os gestos da pesquisadora. Ressaltamos que os meios semióticos, para Radford (2005), se localizam no corpo, nos artefatos e nos signos. (grifo do autor)

Simultâneo ao processo de objetivação há o processo de subjetivação dos estudantes e da pesquisadora durante o desenvolvimento da situação proposta. Segundo Radford (2020), a subjetivação seria uma ação contínua e histórica de criação do eu, do ser social, ou seja, a instanciação do ser, único, singular de cada indivíduo em formação, em constante mudança. Esse processo é caracterizado por reflexões pessoais e sociais, sensibilidades, compreensões, objeções. (RADFORD, 2017)

A pesquisadora, ao indagar ao grupo "se fossem mais pessoas ?", faz um convite aos estudantes diante outras quantidades. A estudante E2 responde ao convite ao dizer que é necessário desenhar mais alguém e contar e, quando olha para o colega E3, obtém uma validação com a afirmação de que o depois sempre soma.

Nesse caso, tem-se o processo de subjetivação juntamente à objetivação no desenvolvimento da situação pelos estudantes e pela pesquisadora. Conforme as interações anteriores, há indícios da ética comunitária, assinalada pela responsabilidade que se constitui de subjetividades, união, conexão e enlace com o outro, expressa na resposta que temos ao chamado do outro. (RADFORD, 2020) 
O Grupo 2 (6TB), composto por três estudantes, produziu uma tabela indicada como uma Representação Regular, por ser frequente em diversos contextos matemáticos -como para expressar uma relação entre área e perímetro, por exemplo, dentre exemplos de outras disciplinas.

A tabela foi apresentada como um modelo em vermelho e azul, em um papelão, dividida em seis partes para indicar uma pessoa em cada. Porém, durante as considerações quanto à resolução da situação, a pesquisadora indaga o grupo sobre o modelo - conforme excerto a seguir- e o estudante E1 gesticula que o modelo em partes poderia ficar confuso, pois teriam que recortar fichas para colocar em cada parte representando a relação entre a quantidade de pessoas/telefonemas.

O grupo então resolveu fazer uma tabela em cartolina branca, conforme Figura 3, expandindo a quantidade inicial de 5 para 10 pessoas.

Figura 3 - Representação Regular do Grupo 2

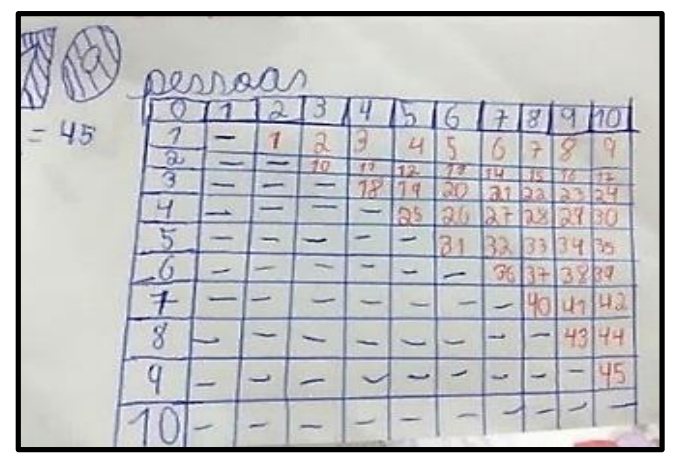

Fonte: protocolo do Grupo 2.

A situação proposta correspondeu ao que destaca Radford; Schubring; Seeger (2008), a respeito do objeto de conhecimento da situação ser dinâmico, multifacetado, em constante mudança, e que não "aparece" para cada estudante com a mesma clareza e entendimento. Concorda-se com a afirmação, pois, no Grupo 2, houve divergências quanto ao modelo proposto, além da quantidade de telefonemas, conforme indica o estudante E3.

E3: Ela achava (olha para E2 e rindo) que 10 pessoas dá 20, porque a gente sabe que 5 dá 10 !’, na qual a estudante E2 se confundiu ao pensar em uma proporcionalidade .

Ao compreender que a soma inicia-se sempre pela quantidade de pessoas menos 1 , o estudante E3 apresenta indícios de objetivação ao encontrar o objeto do conhecimento (a co-variação) enquanto potencialidade, no sentido proposto pela TO, ou seja, atualizando o saber em conhecimento .

E3: “Daí segue a conta para outra pessoa (indica com o dedo a 'pessoa' 2) 10, 11, 12”.

$\mathrm{Na}$ interação a seguir percebemos que ao mobilizar diferentes meios semióticos, tais como: gestos na justificativa quanto as incoveniências de utilizar o modelo em papelão e a tabela apontada na investigação como representação regular por ser presença constante em situações problemas - e 
que já estava sendo utilizada por outro grupo -, como representação apropriada para melhor entendimento possibilita o processo de objetivação.

$P$ : E o modelo em azul e vermelho que fizeram?

E1: Não ia dar pra entender cada pessoa, em cada parte, tipo tabela (aponta com as mãos um gesto de "ida e volta" ao lado do modelo).

\section{E2: Daí, ele (indica que é E3) falou da tabela e a gente mudou [...].}

Do mesmo modo que o Grupo 1, o processo de subjetivação ocorreu entre a pesquisadora ao demonstrar interesse na quantidade de pessoas representadas na tabela, no modelo e em seguida na constatação da quantidade de telefonemas para dez pessoas .

P: Olha só, muito bem . Porque fizeram a tabela para 10 pessoas?

P: E qual o total de ligações para 10 pessoas?

E1: São 45...(gesticula para E2, com ritmo de diminuição de cada linha, para confirmar e mostra a folha com a resolução para a pesquisadora e para o grupo 1 que estava ao lado) a pessoa "1" liga para 9 [...].

Nesse momento, é quando E3 sinaliza que a estudante E2 pensava que 10 pessoas resultaria em 20 telefonemas. O estudante E1 ao gesticular para E2 ,demonstra o cuidado com o outro na explicação da co -variação e não da situação “Quantos telefonemas?”, ser representada por $\mathrm{f}(\mathrm{n})=$ 2n .Entre os estudantes, inferimos o processo de subjetivação com a a afirmação de E1 que seria incompreensível cada pessoa no modelo azul e vermelho em papelão e em seguida a atitude colaborativa de E2 ressaltando a sugestão do estudante E3, ao citar a tabela e a aceitação dos integrantes do grupo.

E2: A gente viu deles (indica um outro grupo que produziu uma tabela de dupla entrada para 5 pessoas) e achou legal. Daí já dava pra ver no desenho (mostra com o lápis de maneira ritmada a tabela) que dava 10 ligações [...].

Assim, segundo Radford (2017), depreende-se que houve além do cuidado com o outro, o compromisso, enquanto o ato de fazer todo o possível, no transcorrer do Labor Comum, para produção do saber materializado- a relação entre as variáveis -, em que os meios semióticos são essenciais nas relações dialéticas entre saber e conhecimento e entre ser e subjetividade.

O Grupo 3, composto por três estudantes, não produziram os modelos em 3D. Eles utilizaram a folha de sulfite com a proposta para discutir ideias de resolução. Em seguida, decidiram fazer desenhos nominados com flechas e determinando a quantidade de ligações conforme Figura 4 .

Nesse ínterim, a estudante E1 levanta-se e começa a gesticular, dramatizando a situação dos telefonemas como se fossem apertos de mão .Nos diálogos a seguir, temos a justificativa de E1 
do porque propôs os apertos de mão, afirmando que o estudante E2 disse que no grupo deles composto de três integrantes -, seriam três apertos e consequentemente na situação proposta, três telefonemas.

P:Como vocês indicaram a quantidade de ligações?

E2: A gente quis fazer os desenhos e dai apertar as nossas mãos.

E1: Só que ele profê (indica que é E2) teimou falando que era só 3 apertos no nosso caso, e que pra 5 pessoas seria 5 ligações.

E2: [...] Não ia dar 5 ligações! A pessoa não liga pra ela mesma, né?!

P: E o que vocês fizeram?

E1: Eu levantei e fui apertando a mão deles (indica 2 estudantes de outro grupo). Daí (mostra E2 e E3) começaram a contar direito [...].

Segundo Vergel,Gárzon (2018,p.69), “o gesto como um meio semiótico de objetivação, desenvolve um papel importante na expressão das intencionalidades dos sujeitos e em seu processo de conceitualização". No excerto anterior, podemos verificar a intencionalidade da estudante E1 em materializar o objeto do conhecimento (quantidades de telefonemas) ao levantar e procurar estudantes de outros grupos indicando responsabilidade com seu grupo de maneira proativa.

A pesquisadora questiona a escolha do desenho, demonstrando interesse na representação idiossincrática produzida pelo grupo .

Figura 4 - Representação Idiossincrática do Grupo 3

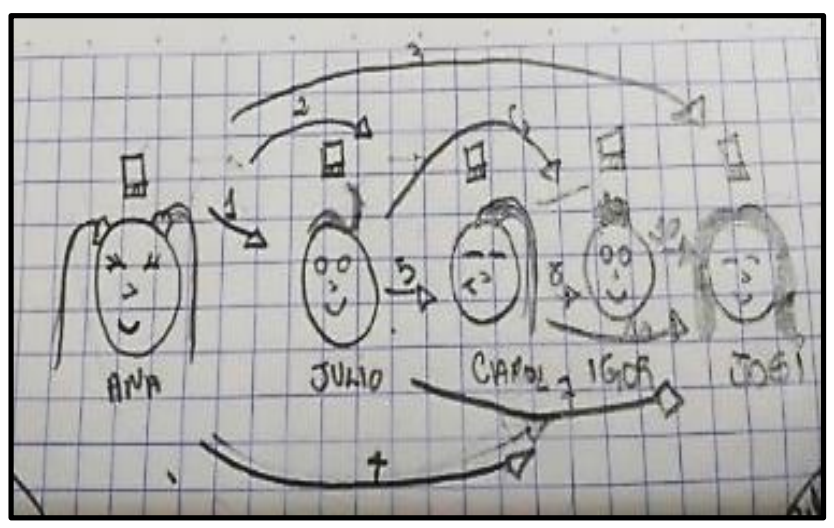

Fonte: protocolo do Grupo 3.

\section{$P:$ E resolveram desenhar?}

E3: Sim, oh (mostra sorrindo a folha quadriculada com a representação idiossincrática) cada pessoa tem a letra do nome daquele "povo" (Direcionou o olhar para o grupo que participou da dramatização). 
E1:Tem os desenhos de cada pessoa e dai (olha empolgado para E3) pensamos nos nomes... Ana ligou pra todo mundo [...]. Ohhh (se inclina para a frente e sinaliza com o lápis o "formato" com as flechas) 1, 2, 3 e 4 da Ana [...].

\section{E3: Daí continua o Julio 5 , 6 e 7 e vai até todo mundo falar com todo mundo.}

E2: Sim, a gente sabia que era só ir somando na ordem [...] a quantidade que começa diminui 1 [...] pra qualquer numero de pessoas!

Verificamos nesse grupo, o processo de objetivação da relação quantidade de pessoas/ telefonemas, indicado pela ultima frase do excerto anterior.Os meios semióticos além dos gestos com o lápis, olhares, representação idiossincrática , também compreende a própria estudante E1 enquanto um meio semiótico ao realizar a dramatização.

Ao indicar com o lápis a quantidade de telefonemas da primeira pessoa na representação, temos indícios de coletividade na co- produção de saberes que segundo Radford (2020), constitui juntamente com a colaboração humana, no labor comum onde os integrantes do grupo sucessivamente apontam a continuidade de telefonemas de cada nome presente no desenho.

De acordo com o trecho a seguir, nota-se que, ao questionar os grupos , a pesquisadora também partcpa doprocsso de subjetivação, em trabalho comum, que possibilitou as soluções para uma mesma atividade proposta. O Labor Comum, em conformidade com o que ressalta Radford (2018), ocorreu como um "ombro a ombro", em que a pesquisadora e os estudantes puderam estar em um trabalho comum, ao pensarem em outras quantidades e juntos na co-variação da proposta.

$P$ : E se fossem mais pessoas então?

E2: Não sei... Espera!

$P:$ (indicando o desenho)

E3: Ahhh... Se fosse 7 era fazer 6+5+4 [...]. (Olhando para E1, em dúvida).

E1: Isso sempre o tanto do começo, menos uma pessoa! (Disse olhando para E3).

Quanto aos estudantes, as subjetivações foram inferidas ao ouvirem as dúvidas dos colegas e considerarem os questionamentos da pesquisadora, no compartilhamento de infomaçoes, no sentir e o agir junto e o respeito ao ouvir os outros na elaboração de uma ideia comum - por exemplo -, a empolgação da estudante E1 ao dizer que pensaram juntos os nomes presentes na representação.

Aspectos diversos das características do Pensamento Algébrico segundo Kaput; Carraher; Blanton (2008), que podem realizados pelos alunos, como: simbolizar quantidades e operar com expressões simbólicas; representar dados graficamente; estabelecer relações funcionais; prever resultados desconhecidos, foram apresentados durante o desenvolvimento da situação proposta pelos grupos G1, G2 e G3. 
As interações dialógicas entre os grupos foram fundamentais para inferir o labor comum constituído pelos processos simultâneos de objetivação e subjetivação numa relação dialética entre os envolvidos, ancorados nas ideias do saber materializado pela mobilização dos meios semióticos e no eu comunitário propostas pela TO. Radford (2018) destaca que o "eu comunitário" se relaciona ao outro, com estar ocupado em aprender como interagir com os outros para abrir-se à compreensão de outras vozes e outras consciências ,em uma ética comunitária fundamentada na responsabilidade, no compromisso e cuidado com o outro.

Radford (2020) sublinha que não é simplesmente dar 'voz' ao estudante, tampouco a interação entre grupos de estudantes e professor que indica a objetivação e consequentemente a subjetivação. Sem a ética comunitária pode haver ações compartilhadas, porém, não o Labor Comum.

A dimensão social que envolve estudantes e professores não é mediadora da aprendizagem, não é somente um momento específico no cenário de uma aula, mas a essência do Labor Comum enquanto parte inteira da aprendizagem, ou seja, é um fim em si mesma. (RADFORD, 2020).

\section{Considerações finais}

A atividade proposta "Quantos telefonemas?" faz parte de uma pesquisa de doutorado em andamento cuja investigação se pauta nos elementos que emergem de situações da Early Álgebra com estudantes do $6^{\circ}$ ano do Ensino Fundamental II, a partir de uma teoria da Educação Matemática com abordagem semiótica. Objetivamos evidenciar os processos de objetivação e subjetivação decorrentes do Labor Comum, assim como a mobilização dos meios semióticos e indícios de características do Pensamento Algébrico.

As indicações da BNNC (2018) quanto a importância de oportunizar aos estudante situações que contemplem ideias de regularidade, variação, equivalência e indícios de generalização vem ao encontro do que propõe a Early Álgebra, no sentido de promover essas situações enquanto complementaridade no ensino de Aritmética, e não em detrimento dele. Na situação apresentada aqui identificamos um indício do Pensamento Algébrico na relação entre as variáveis "pessoas e telefonemas", e, além disso, inferimos que situações do contexto da Early Álgebra podem estimular a mobilização de diversos meios semióticos.

A Teoria da Objetivação, enquanto abordagem semiótica, permitiu a análise das formas de produção de saberes e colaboração humana, destacados por Radford (2020), em processos de objetivação e subjetivação ocorridos de modo mútuo, contínuo e justapostos. O Labor Comum. como resultado das relações dialéticas entre saber/ e ser/ subjetividade, enriqueceu a produção de 
representações regulares e idiossincráticas e a mobilização de outros meios semióticos (gestos, ritmo, expressões faciais, indicações com artefatos, modelos 3D) na significação da proposta.

Os meios semióticos contribuíram para o processo de objetivação na percepção significativa de que algo se constituía como potencialidade: a relação entre variáveis atuando como mediador na materialização do saber do indício de pensamento algébrico, a covariação, por meio do estabelecimento de relações numéricas entre as duas variáveis em causa e a quantidade de pessoas e telefonemas efetuados.

Verificamos, também, que um dos meios semióticos recorrentes foram os gestos, ao indicar quantidades nas linhas coloridas, traços, legenda, algoritmos, nos modelos e representações, além da estudante E1 do Grupo 3 que ao dramatizar a situação, tornou-se um meio semiótico.

A subjetivação ocorreu concomitante ao processo de objetivação com indicativos do devir, isto é, a constituição do(s) outro(s) estudante(s) e da pesquisadora - a partir dos diálogos, indagações e reflexões ancorados na ideia de ética comunitária proposta pela TO, sublinhados pelo compromisso, respeito e cuidado para/e com o outro.

No processo dialético que envolveu a pesquisadora e o(s) estudante(s) houve uma interação dinâmica, em que a pesquisadora questionou estratégias, ouviu com atenção e sensibilidade as sugestões do(s) estudante(s), ampliando as discussões para o coletivo da sala de aula na co-produção de saberes e colaboração humana.

\section{Referências}

BRASIL. Ministério da Educação. Base Nacional Comum Curricular: Educação é a base. Educação Básica. Brasília: MEC, 2018.

CAMILOTTI, Dirce, GOBARA, Shirley. Formação Continuada de professores de Ciências : Indícios do processo de subjetivação. In: Shirley, GOBARA; Luis, RADFORD. Teoria da Objetivação: Fundamentos e Aplicações para o Ensino de Ciências e Matemática. São Paulo: Livraria da Física, 2020, p.225-246.

CANAVARRO, Ana Paula. O pensamento algébrico na aprendizagem da Matemática nos primeiros anos. Quadrante, v. 16, n. 2, p. 81-118.2007.

CASTILHO, Raquel. O “ encontro” com o mapa : aprendendo a pensar sobre o espaço por meio do sistema semiótico cartográfico. In: Shirley, GOBARA; Luis, RADFORD. Teoria da Objetivação: Fundamentos e Aplicações para o Ensino de Ciências e Matemática. São Paulo: Livraria da Física, 2020,p. 175-197. 
D’AMORE, Bruno. Primeiros Elementos de Semiótica sua presença e importância no processo de ensino -aprendizagem da matemática. São Paulo: Livraria da Física, 2015.

GOLDIN, Gerald. Representation in mathematical learning and problem solving. Handbook of International Research in Mathematics Education. Mahwah, NJ: Lawrence Erlbaum Associates.2002.

KAPUT, James; CARRAHER, David; BLANTON, Maria. Algebrain the Early Grades. New York: Lawrence E. A., 2008.

KIERAN, Carolyn. The Learning and Teaching of School Algebra. Handbook of Research on Mathematics Teaching and learning. New York: Macmillan.1992.

LINS, Rômulo Campos; GIMENEZ, Joaquim. Perspectivas em Aritmética e Álgebra para o século XXI. Campinas: Papirus, 1997.

LUDKE, Menga; ANDRÉ, Marli E.D.A. Pesquisa em Educação: Abordagem qualitativas. São Paulo: Editora E.P.U, 2013

MESTRE, Célia. O desenvolvimento do pensamento algébrico de estudantes do $4 .^{\circ}$ ano de escolaridade: Uma experiência de ensino. Lisboa: Universidade de Lisboa, 2014.p.357.

NCTM. Principles and standards for school mathematics,2008. http://www.nctm.org/standards/ NOGUEIRA, Mayara. Diálogos entre ciências e ficção científica: uma estratégia para discutir ética científica baseada na teoria da objetivação. Natal: Universidade Federal do Rio Grande do Norte, 2019, 210 f. (Tese doutorado em Ensino de Ciências e Educação Matemática).

NOROÑO, Irene et al. Sobre os processos de objetivação de saberes geométricos. Análise de uma experiência de elaboração de simuladores com o GeoGebra. Educación Matemática, v. 32, n. 1, p.99-131, 2020.

RADFORD, Luis. Gestures, speech, and sprouting of signs. Mathematical Thinking and Learning. v. 5, n.3. p. 37-70, 2003.

Elementos de una teoría cultural de la objetivación. Revista Latinoamericana de Investigación en Matemática Educativa, v. 9, n. 1, pp. 103-129, 2006.

RADFORD, Luis, SCHUBRING, Gert, SEEGER, Falk. Semiotics in Mathematics Education: Epistemology, History, Classroom, and Culture, Boston: Sense Publishers, 2008.

Introduction: The phenomenological, epistemological, and semiotic components of generalization. PNA, v. 9, n. 3, pp. 129-141, 2015.

A Teoria da Objetivação e seu lugar na pesquisa sociocultural em Educação Matemática. In: Vanessa, MORETTI; Wellington, CEDRO. Educação Matemática e a Teoria HistóricoCultural: Um olhar sobre as pesquisas. Campinas: Mercado de Letras, 2018. p. 229-261 
eISSN: $2526-9062$

. Aprendizaje desde la perspectiva de la teoría de la objetivación. In: D’AMORE, Bruno; RADFORD, Luis (Orgs.). Enseñanza y aprendizaje de las matemáticas: problemas semióticos, epistemológicos y culturales. Bogotá: Universidad Distrital Francisco José de Caldas, 2017. p. 115136

. Algunos desafíos encontrados en la elaboración de la teoría de la objetivación. PNA, v. 12, n. 2, pp. 61-80, 2018.

. Un recorrido a traves de la Teoria de la Objetivación. In: Shirley, GOBARA; Luis, RADFORD. Teoria da Objetivação: Fundamentos e Aplicações para o Ensino de Ciências e Matemática. São Paulo: Livraria da Física, 2020. p.15-42

SANTAELLA, Lúcia. Matrizes da linguagem e pensamento: sonora, visual, verbal: aplicações na hipermídia. São Paulo: Iluminuras-FAPESP, 2005.

VERGEL, Rodolfo. El signo en Vygotsky y su vínculo con el desarrollo de los processos psicológicos superiores. Folios, n. 39, pp. 65-76, 2014.

VERGEL, Rodolfo; GÁRZON, Pedro J. R. Álgebra escolar y pensamiento algebraico: aportes para el trabajo en el aula. Bogotá: Editorial Universidad Distrital Francisco José de Caldas, 2018. VYGOTSKY, Lev S. Linguagem, desenvolvimento e aprendizagem. São Paulo: Ícone, 1984. 